Prepared for the U.S. Department of Energy

under Contract DE-AC05-76RL01830

\title{
Resource Form Factor and Installation of GFA Controllers
}

\author{
JG DeSteese \\ DJ Hammerstrom
}

November 2009

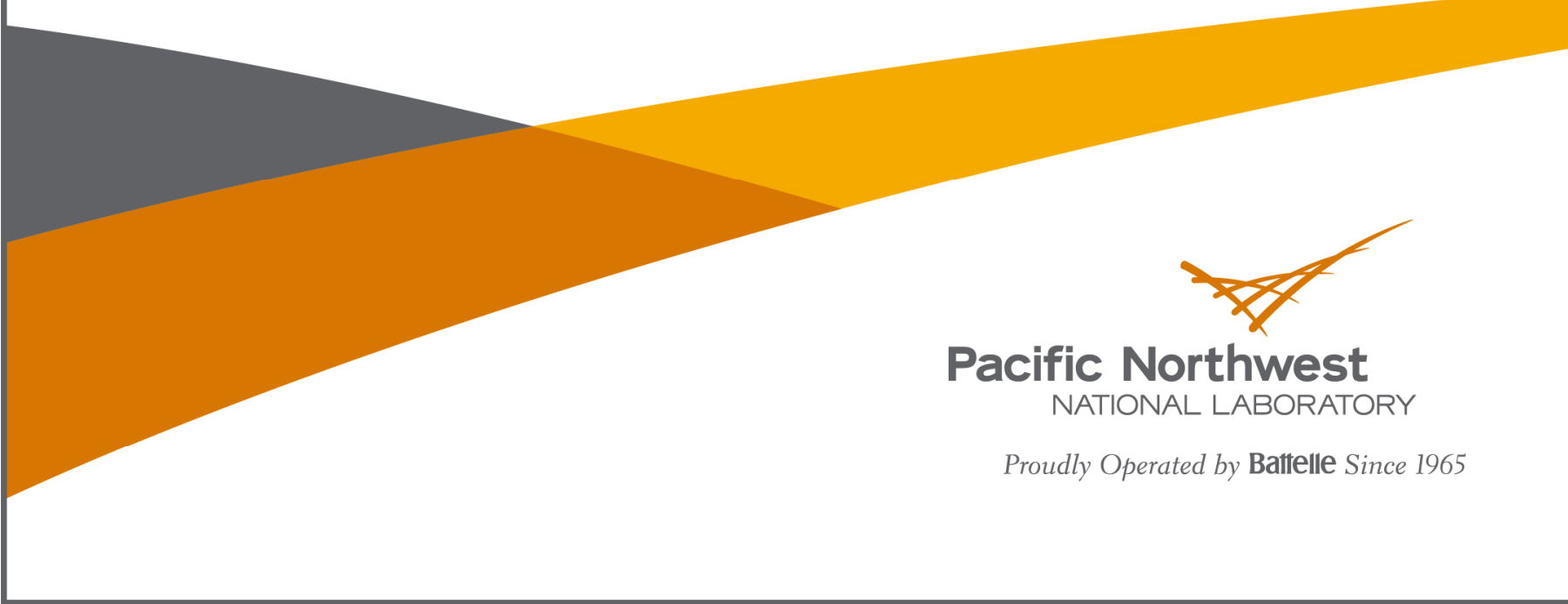




\title{
DISCLAIMER
}

This report was prepared as an account of work sponsored by an agency of the United States Government. Neither the United States Government nor any agency thereof, nor Battelle Memorial Institute, nor any of their employees, makes any warranty, express or implied, or assumes any legal liability or responsibility for the accuracy, completeness, or usefulness of any information, apparatus, product, or process disclosed, or represents that its use would not infringe privately owned rights. Reference herein to any specific commercial product, process, or service by trade name, trademark, manufacturer, or otherwise does not necessarily constitute or imply its endorsement, recommendation, or favoring by the United States Government or any agency thereof, or Battelle Memorial Institute. The views and opinions of authors expressed herein do not necessarily state or reflect those of the United States Government or any agency thereof.

\author{
PACIFIC NORTHWEST NATIONAL LABORATORY \\ operated by \\ BATTELLE \\ for the \\ UNITED STATES DEPARTMENT OF ENERGY \\ under Contract DE-AC05-76RL01830
}

Printed in the United States of America
Available to DOE and DOE contractors from the Office of Scientific and Technical Information,
P.O. Box 62, Oak Ridge, TN 37831-0062;
ph: (865) 576-8401
fax: $(865)$ 576-5728
email: reports@adonis.osti.gov

\begin{abstract}
Available to the public from the National Technical Information Service, U.S. Department of Commerce, 5285 Port Royal Rd., Springfield, VA 22161 ph: (800) 553-6847 fax: $(703) 605-6900$ email: orders@ntis.fedworld.gov online ordering: http://www.ntis.gov/ordering.htm
\end{abstract}

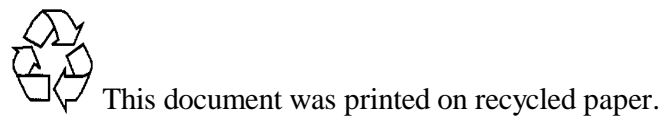




\section{Resource Form Factor and Installation of GFA Controllers}

JG DeSteese

D Hammerstrom

November 2009

Prepared for

the U.S. Department of Energy

under Contract DE-AC05-76RL01830

Pacific Northwest National Laboratory

Richland, Washington 99352 



\begin{abstract}
The focus of this task is to optimize the form and placement of a controller comprising the Grid Friendly ${ }^{\mathrm{TM}}$ appliance (GFA) controller, power supply and power relay (and/or a solid-state power electronic switch) that would command a domestic water heater to shed its load in response to stress on the electric power grid. The GFA controller would disconnect the water heater from its supply circuit whenever it senses a low voltage signal or other indicators of system stress communicated via the electric power distribution system. Power would be reconnected to the appliance when the GFA controller senses the absence of these signals. This project has also considered more frequent cycling of this controller's relay switch to perform demand-side frequency regulation. The principal criteria considered in this optimization are reliability, cost and life expectancy of the GFA components. The alternative embodiments of the GFA equipment under consideration are:

- Option 1 - installation inside the insulation space of the water heater between the tank and jacket

- Option 2 - containment in a separate nearby electrical enclosure

- Option 3 - as a modification or adjunct to the distribution panel housing and/or the breaker that protects the water heater supply circuit.

Option 1 was estimated to be the preferable choice from the aggregate perspective of having adequate reliability and life expectancy combined with the lowest life cycle cost. Option 2 has advantages of inherently lower thermal aging of components and a life expectancy extending well beyond two average appliance lifetimes. Option 3 can be eliminated from further consideration because of its relative complexity, lower reliability and extreme cost.
\end{abstract}





\section{Contents}

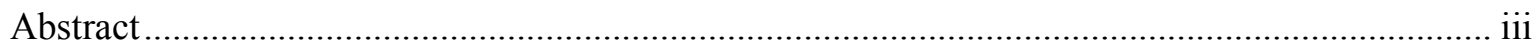

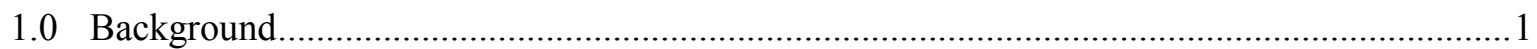

1.1 Option 1 - GFA Controller Integral with Water Heater.................................................... 1

1.2 Option 2 - GFA Controller Contained in Separate Enclosure ........................................ 1

1.3 Option 3 - GFA Controller as an Adjunct of Circuit Breakers in the Distribution Panel..2

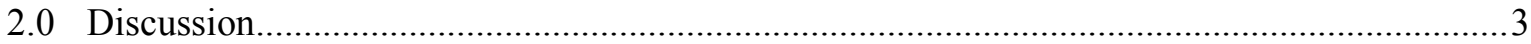

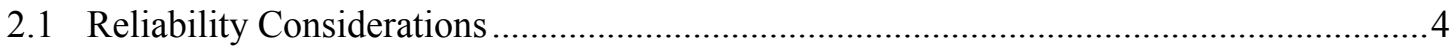

2.1.1 Perspective on Water Heater Life Expectancy ......................................................

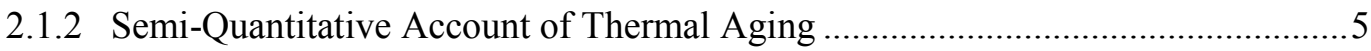

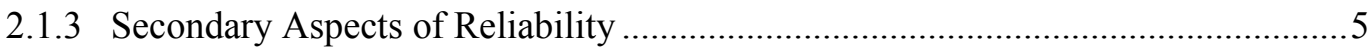

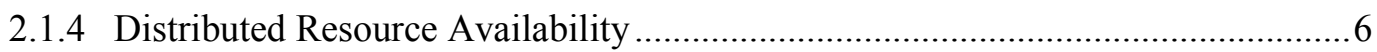

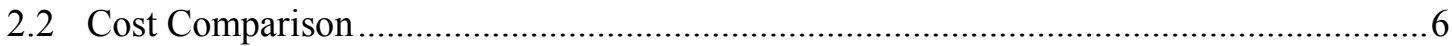

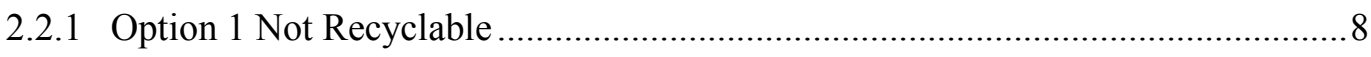

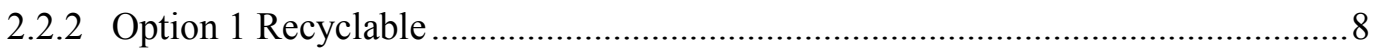

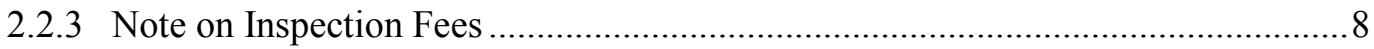

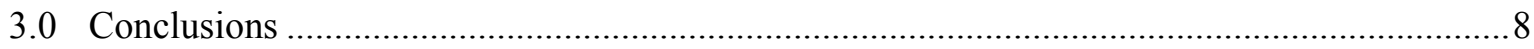

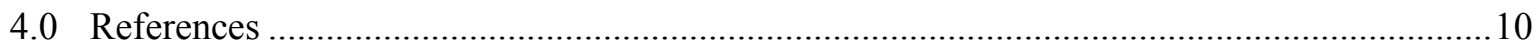

\section{Tables}

1 Advantages and Disadvantages of Configuration and Placement Alternatives .......................2

2 Comparison of Cost to Equip the First Water Heater .............................................................. 7 



\subsection{Background}

This analysis considers the relative merits of three alternative forms in which a GFA controller may be installed in a private residence to control the energy consumption of an electric water heater. Because of its thermal storage capacity, a water heater can be temporarily disconnected from the electricity supply without the loss of electrical power affecting the performance or availability of the appliance from the owner's perspective. The GFA controller would alternatively interrupt and restore power to the water heater upon receiving appropriate voltage or frequency signals transmitted over the distribution grid that correspond to the level of stress the grid is experiencing. A GFA-controlled, tank-type water heater is thus an ideal means by which an electric utility could acquire a distributed load control capability that automatically assists power grid management when it is under stress. The field project known as the "Pacific Northwest GridWise Testbed Demonstration" [Hammerstrom et al. 2007] successfully demonstrated this concept using system underfrequency sensing as the means for effecting GFA control of many water heaters. The work discussed here reviews the reliability and cost aspects of alternative approaches for packaging and integrating the GFA controller in this type of application.

\subsection{Option 1 - GFA Controller Integral with Water Heater}

In this configuration, GFA controller components including the GFA microprocessor and logic board, a power supply and power relay (and/or a solid-state power electronic switch) would be contained in a preferably metal enclosure or shield mounted inside the insulation space of the water heater between the tank and jacket. It would function as a smart circuit breaker between the water heater's 208/240-V high-limit thermostat assembly and the upper and lower thermostats.

This option presents opportunities that are not easily realized by the other options. Because of the proximity of the controller to the water heater, water temperature may be readily metered using this option, and the water temperature may then be used to modify the controller's response. An improved algorithm can then better ensure the customer's comfort and adequate water temperature. Availability of water temperature also allows water temperature to be electronically regulated by the controller. Thus small variations in water temperature can be controlled both above and below the regulated set point, providing both up- and down-regulation services.

Variants of this option include the GFA controller being engineered and installed by the manufacturer or installed by a certified electrician as an after-market modification. In both alternatives, a prerequisite assumption is that the GFA controller would be designed to comply with Underwriters Laboratories Inc. (UL) "Standard for Safety for Temperature-Indicating and -Regulating Equipment, UL-873." [Underwriters Laboratories Inc. 2007].

\subsection{Option 2 - GFA Controller Contained in Separate Enclosure}

The second option uses the identical GFA components of Option 1 but mounted in a separate nearby electrical enclosure. This enclosure would typically be a polycarbonate box with a screw-attached lid mounted on a wall or other appropriate surface in the vicinity of the water heater. This, in effect, enables the electrical circuit supplying the water heater to be "grid-friendly" independent of the appliances it serves. Most commercially available water heater load controllers use this form factor option. 


\subsection{Option 3 - GFA Controller as an Adjunct of Circuit Breakers in the Distribution Panel}

This, in essence, is a variant of Option 2 in making the entire supply circuit, not just the appliance, grid responsive. Option 3 attempts to take advantage of possible synergy with the breaker panel as a ready-made housing for the GFA controller or otherwise, to integrate a GFA capability into the circuit breaker at its conventional location. Two subsets of the latter alternative include (1) using GFA controller signals to activate an advanced breaker residing in the distribution panel via an external communications link or (2) integrating the entire GFA function into the breaker case.

Table 1 provides a first-order summary comparison of the advantages and disadvantages of the three alternatives. As will be discussed below, recent design innovations mitigate most disadvantages listed for Option 1.

Table 1. Advantages and Disadvantages of Configuration and Placement Alternatives

\begin{tabular}{|c|c|c|}
\hline Alternative & Advantages & Disadvantages \\
\hline $\begin{array}{l}\text { Option 1: } \\
\text { Smart controller, power supply and } \\
\text { power electronic on/off switch } \\
\text { mounted inside water heater jacket }\end{array}$ & $\begin{array}{l}\text { - Simple installation for OEM or } \\
\text { retrofit } \\
\text { - Can be substituted for metal link } \\
\text { that connects the high-limit } \\
\text { thermostat to the upper and } \\
\text { lower thermostats. } \\
\text { GFA control components } \\
\text { contained within appliance, } \\
\text { perhaps useful for additional } \\
\text { smart control objectives, } \\
\text { including communicated demand } \\
\text { response requests } \\
\text { - Uses appliance structure for } \\
\text { housing } \\
\text { - Part of waste heat produced by } \\
\text { power switch may be recovered } \\
\text { in hot water }\end{array}$ & $\begin{array}{l}\text { - Controller likely to be discarded at } \\
\text { end of appliance life } \\
\text { - Subject to thermal aging and } \\
\text { reduced reliability because of } \\
\text { ambient heat from appliance } \\
\text { - Subject to thermal aging and } \\
\text { reduced reliability because of } \\
\text { reduced ability to dissipate own } \\
\text { power electronic heat } \\
\text { May require engineered heat sink } \\
\text { or conduction path through tank } \\
\text { insulation to avoid destructive } \\
\text { heat build up } \\
\text { - Subject to mechanical damage } \\
\text { if/when appliance needs repair }\end{array}$ \\
\hline $\begin{array}{l}\text { Option 2: } \\
\text { Smart controller, power supply and } \\
\text { power electronic on/off switch } \\
\text { mounted in separate electrical box } \\
\text { outside but in vicinity of water heater }\end{array}$ & $\begin{array}{l}\text { - Simple installation or retrofit } \\
\text { - Control function contained and } \\
\text { protected within own electrical } \\
\text { box } \\
\text { - Inherent long life reliability } \\
\text { - Useful life independent of } \\
\text { appliance life } \\
\text { - Reduced thermal stress and } \\
\text { mechanical damage risk } \\
\text { - Not exposed to potential of } \\
\text { damage if appliance is repaired } \\
\text { - Sufficient volume and surface } \\
\text { area to dissipate power switch } \\
\text { heat }\end{array}$ & $\begin{array}{l}\text { - Additional cost of electrical box, } \\
\text { mounting components } \\
\text { - After-market installation labor and } \\
\text { inspection fee }\end{array}$ \\
\hline
\end{tabular}


Table 1. contd

\begin{tabular}{|c|c|c|}
\hline Alternative & Advantages & Disadvantages \\
\hline $\begin{array}{l}\text { Option } 3 \text {, Variant } 1 \text { : } \\
\text { Smart controller, power supply and } \\
\text { power electronic on/off switch } \\
\text { mounted in power distribution panel } \\
\text { containing conventional } \\
\text { thermal/magnetic circuit breakers }\end{array}$ & $\begin{array}{l}\text { - Simple installation or retrofit } \\
\text { - Physically protected by } \\
\text { distribution panel housing } \\
\text { - Sufficient volume and surface } \\
\text { area to dissipate power switch } \\
\text { heat } \\
\text { - Inherent long life reliability } \\
\text { - Useful life independent of } \\
\text { appliance life } \\
\text { - Minimal thermal stress and } \\
\text { physical damage risk }\end{array}$ & $\begin{array}{l}\text { - May be subject to Electrical Code } \\
\text { restrictions regarding placement in } \\
\text { a conventional electrical } \\
\text { distribution box } \\
\text { - Produces heat from power switch } \\
\text { inside circuit breaker panel } \\
\text { enclosure } \\
\text { - Adds wiring complexity inside } \\
\text { circuit breaker panel enclosure } \\
\text { - After-market installation labor and } \\
\text { inspection fee }\end{array}$ \\
\hline $\begin{array}{l}\text { Option 3, Variant 2: } \\
\text { Smart controller, power supply and } \\
\text { power relay built integral or } \\
\text { communicating with advanced } \\
\text { circuit breaker }\end{array}$ & $\begin{array}{l}\text { - Smart control function built into } \\
\text { circuit breaker } \\
\text { - Simple retrofit in existing } \\
\text { breaker panel } \\
\text { - No additional installation } \\
\text { required to control any appliance } \\
\text { - Life of controller independent of } \\
\text { appliance life } \\
\text { - Universal application to } \\
\text { appliances on any circuit }\end{array}$ & $\begin{array}{l}\text { - Not yet commercially available } \\
\text { manufacturing capability and } \\
\text { product qualification against } \\
\text { applicable codes and standards } \\
\text { - Preferably built in as smart switch } \\
\text { that functions independently of } \\
\text { mechanical protective functions of } \\
\text { circuit breaker } \\
\text { - If mechanical contacts are } \\
\text { actuated by the smart controller, } \\
\text { rapid aging of breaker components } \\
\text { would occur when operating at a } \\
\text { frequency of several switches per } \\
\text { day } \\
\text { - A circuit breaker with an integral } \\
\text { smart controller may not be able } \\
\text { to provide mechanical isolation of } \\
\text { load circuit when desired } \\
\text { - Smart controller could } \\
\text { compromise a breaker's } \\
\text { conventional circuit protective } \\
\text { functions } \\
\text { After-market installation labor and } \\
\text { inspection fee }\end{array}$ \\
\hline
\end{tabular}

\subsection{Discussion}

Each of the above options and secondary alternatives provide the identical function of enabling domestic water heaters to operate as a distributed load control resource that is automatically activated when the grid experiences stress. All contain an identical GFA controller including an electronic microprocessor, power supply and power relay. Reliability and cost comparisons of Options 1 and 2 are 
driven by the consequences of the location and type of enclosure each employs. Option 3 , in the form of any of its variants involves additional components, complexity or the need for new product development. The following section considers the relative reliability of the options.

\subsection{Reliability Considerations}

In general, the failure rate versus time curve for any system typically has a "bathtub" shape characterized by three distinguishable regions: (1) an early period of relative high failure rates principally attributable to random "infant mortality" causes; (2) a stable period with relatively low failure frequency and (3) a final period with increasing failure rates when components wear out. All of the options would be vulnerable to infant mortality failures; however, the majority of these should occur within the first year of operation and would likely be repairable under warrantee. In this respect, Option 1 would have an advantage if the GFA controller were built in by the original equipment manufacturer (OEM). An aftermarket, on-site installation of the controller in any of the three form options would likely have less warrantee protection.

A recent GFA controller design innovation interrupts and reconnects power to the water heater at the zero-crossing point of the ac current wave by means of a solid-state switch, such as a silicon controlled rectifier (SCR), and then maintains the circuit with an electromechanical latching relay. This concept offers considerable improvements in reliability and life expectancy as well as reduced power consumption and very little heat generation in all the alternatives. The innovation frees the GFA controller from the constraint of switching the relay under power which improves its operational life expectancy from about 100,000 cycles to several million. With relay life extended by one to two orders of magnitude, the next likely cause of failure would be thermal aging that promotes migration and/or corrosion of materials inside the solid state components of the controller. Because the design of the GFA controller is not yet finalized, it is currently difficult to estimate the reliability of the options quantitatively. However, the following considerations are applicable.

\subsubsection{Perspective on Water Heater Life Expectancy}

As noted above, relay cycle life previously represented the principal anticipated life-limiting component of the GFA controller. Anticipated frequency of relay actuations will be a function of the target application (e.g., underfrequency load shed, frequency regulation, and so on) and emerging grid conditions over the lifetime of the controller. Hypothetically, if the relay were to be activated in the power interrupting mode, say, 10 times a day on average, it would exhaust its 100,000 cycle life in about 27 years. Statistically, the typical life of a domestic water heater ranges from a low of 10 years to a high of 18 years with 14 years being average [Appliance Magazine 1995]. Freed from the relay life constraint by switching at zero current and with conservative design of other components, the GFA controller should be capable of remaining functional for up to three lifecycles of the average water heater (i.e., about 42 years). It is debatable whether or not such a long GFA controller life could be exploitable in practice because of (1) controller design obsolescence, (2) the anticipated appearance of better technology, and (3) the disappearance of support infrastructure that would occur over such a long period. It seems reasonable, therefore, to limit both the reliability and also the cost comparison to a period equivalent to two average water heater lifetimes (i.e., 28 years). 


\subsubsection{Semi-Quantitative Account of Thermal Aging}

Given the commonality of components, thermal aging is likely to be the major consideration that would differentiate the reliability of the options. In the worst case, Option 1 would require continual operation of the controller's components close to $60^{\circ} \mathrm{C}$ (the typical upper set point of the water heater's thermostat). It should be noted that many homeowners set these thermostats lower to achieve more energy economy. Extrapolating the results of a recent PNNL laboratory demonstration suggests that a GFA controller in the form of Option 1 would be thermally "clamped" to the tank temperature with the application of a thermal blanket around the outer jacket. In contrast, the controller components of the other two options should stay within $10^{\circ} \mathrm{C}$ of room temperature $\left(\sim 20^{\circ} \mathrm{C}\right)$.

Considerable work on thermal aging can be found in the literature. Unfortunately, little has been found that is relevant to the present issue. One useful source accessible via the Internet is Eng-Tips Forums Intelligent Work Forums for Engineering Professionals [Eng-Tips Forums 2009]. This forum provided some validation for the rule-of-thumb that the life expectancy of electronic components will be shortened or lengthened by a factor of 2 for every $10^{\circ} \mathrm{C}$ increase or decrease, respectively, in operating temperature. This reference also cites the expectation that electronic microprocessors should survive life tests of 1000 hours at $125^{\circ} \mathrm{C}$ with zero fallout.

Applying the above to the Option 1 configuration with its components operating at, say, $65^{\circ} \mathrm{C}$ suggests that its zero-fallout life (i.e., life expectancy beyond the infant mortality stage) would increase in relation to 1000 hours at $125^{\circ} \mathrm{C}$ by a factor of $2^{6}$ or 64 . This equates to 64,000 hours or 7.3 years. In contrast, Options 2 and 3 should operate at $25^{\circ} \mathrm{C}$ with a life expectancy of $2^{10} \mathrm{x} 1000$ hours, or about 117 years. On this basis, Option 1 appears to be less than adequate to support even a single water heater lifetime, whereas Options 2 and 3 have more than four times the life of the application.

The original reason to thermally sink the controller to the hot water tank was to recover the heat it generates, about $20 \mathrm{~W}$ in the previous design. Recovering this would have resulted in only a small extra benefit worth about $\$ 10$ per year. Now that a non-dissipative electronic switch is being considered, there is essentially no value in attempting to recycle the controller's heat generation. Thus, having it thermally controlled instead by the jacket or an otherwise lowest accessible temperature of the water heater housing would decrease the controller's vulnerability to thermal aging. Operating Option 1 at $55^{\circ} \mathrm{C}$ would give it a life expectance of 14.6 years about equal to the average life of the water heater. Operating at $45^{\circ} \mathrm{C}$ would double this to 29.2 years. From a practical perspective, therefore, Option 1 possesses design latitude that would make it negligibly less reliable than the other options in this application.

\subsubsection{Secondary Aspects of Reliability}

Beyond heat stress, other characteristics that distinguish the options from each other could have reliability implications. Because the Option 1 configuration could be exposed to physical contact or manipulation by the owner if he or she removed the access plate to adjust the thermostat, the GFA controller's reliability could be impacted by accidental damage to a somewhat higher degree than the other options. In Options 2 and 3, there would be no reason for a non-professional to open the case containing the controller. The housings of Options 2 and 3 would, however, be possibly vulnerable to impacts from falling objects and equipment being handled or moved in their vicinity. The slightly higher intrinsic risk of human induced damage to Option 1 would also be mitigated by its design being compliant 
with UL 873. No statistics have been found to quantify these risks. In the limit, none of these second order risks seem as significant as thermal aging discussed above. Thus, from the aspect of mechanical mishandling or accidental damage, none of the options has a distinct advantage or disadvantage.

The reliability of Option 3 is likely to be inferior to both the other options because of its added complexity. In principle, this alternative could use a breaker with remote controlled trip capability of the type represented by the Square D Micrologic ${ }^{\circledR}$ Units made available by Schneider Electric [Schneider Electric 2009]. These units are programmable and can be tripped by many different stimuli. The need for a communication link from the GFA electronics board and the breaker's own internal logic add components with finite failure propensities. Without detailed knowledge of the design of this option, it can still be considered intrinsically less reliable than Options 1 and 2 when they perform the same function with fewer components.

\subsubsection{Distributed Resource Availability}

The bottom line on reliability from the utility's perspective is being able to rely on the availability of the demand-response resource represented by many grid-signal responsive water heaters distributed throughout a control area. Statistically, the GFA controller in a small fraction of these units would be non-functional at any given time for a number of different reasons ranging from component malfunctions to the homeowner's need or desire to manually open the circuit breaker (as might occur during the owner's vacation). Considering the experience gained from a small sample in the Pacific Northwest GridWise Testbed Demonstration, it is expected that between $95 \%$ and $99 \%$ of controlled water heaters in a large population of, say, $>10,000$ units would be latently capable of activation on demand as a dispatchable load control resource. However, greater uncertainty in on-demand availability would be driven by several factors including the nature of the control algorithm, load diversity, time of day, etc. that are beyond the scope of consideration in the present work. With experience in operating a population of GFA appliances, the statistical nature of these effects would become apparent as a basis for the utility's being able to dispatch the resource when required, at a definable level of confidence.

One aspect of design that could contribute to the utility's becoming aware of controller failures would be to ensure that units fail in the open-circuit mode and include an alarm to inform the homeowner this had occurred. The owner would be provided with an " 800 " telephone number to report the problem and seek restoration. The utility could log such calls to update a roster of unavailable units. A similar call would be needed following repairs to account for units restored to operation. In the absence of an ability to interrogate the functionality of controlled appliances via the grid or other remote means, the call-in system could add a measure of confidence in estimating the overall availability of the distributed resource.

\subsection{Cost Comparison}

Table 2 shows a cost comparison based on components needed to equip the first water heater with a GFA controller of each configuration. These costs are in addition to the cost and inspection fee for the water heater itself. Component prices were obtained from the web-based catalogs of large electronic parts distributors such as Digi-Key Corporation [Digikey 2009] reflecting quantity discounts for purchases of 
1000 or more units. The price of a single-chip GFA controller was taken from a vendor supplied estimate solicited by PNNL. The costs of the options are distinguished by the following features:

- Option 1 is estimated on the basis of the GFA controller being installed by the manufacturer of the water heater

- Costs of electronic components in Option 1 are double those of same components in other options to account for manufacturer mark up

- Option 1 will involve no separate inspection fee because the GFA controller is supplied as a manufactured assembly inside the water heater jacket whereas Options 2 and 3 would require inspection of both the water heater and the separate GFA controller

- The electrical box item for Option 1 may be simply a UL-873 compliant shield and is, therefore, likely to be less expensive than the stand-alone boxes required for Options 2 and 3

- Because of low heat generation, Options 2 and 3 do not require an engineered heat sink whereas Option 1 will require this component to minimize the temperature of its electronic components inside the water heater jacket.

Table 2. Comparison of Cost to Equip the First Water Heater

\begin{tabular}{|c|c|c|c|}
\hline Cost Components ${ }^{(a)}$ & $\begin{array}{c}\text { Option 1 } \\
\text { Controller Inside Water } \\
\text { Heater Jacket }(\$)\end{array}$ & $\begin{array}{c}\text { Option } 2 \\
\text { Controller in Electrical } \\
\text { Box on Supply Circuit }(\$)\end{array}$ & $\begin{array}{c}\text { Option3 } \\
\text { Controller with } \\
\text { Advanced Circuit } \\
\text { Breaker (\$) }\end{array}$ \\
\hline GFA Controller & 9.50 & 4.75 & 4.75 \\
\hline 5-V DC Power & 10.00 & 5.00 & 5.00 \\
\hline $\begin{array}{l}\text { Power Relay and/or } \\
\text { Solid-state Switch }\end{array}$ & $33.84 \mathrm{and} /$ or 4.16 & 16.92 & 16.92 \\
\hline Heat Sink & 4.00 & 2.08 & 2.08 \\
\hline Electrical Box & 7.60 & N/A & N/A \\
\hline Electronic Breaker & N/A & 15.00 & 15.00 \\
\hline Breaker Trip Link & N/A & N/A & $>2000$ \\
\hline Installation Labor & N/A & $\mathrm{N} / \mathrm{A}$ & 15 \\
\hline Inspection Fee & N/A & $180^{(b)}-20.00$ & $180^{(b)}-20.00$ \\
\hline Total & $69.10^{(\mathrm{c})}$ & 243.75 & $>2258.75$ \\
\hline
\end{tabular}

(a) Hardware component prices compared for quantity discounts applicable to the acquisition of a 1000 or more units from distributors

(b) $1.5 \mathrm{hr}$ x $\$ 120 / \mathrm{hr}$ professional electrician

(c) Total cost of hardware components double distributor price assuming 100\% mark up by manufacturer or installer. 


\subsubsection{Option 1 Not Recyclable}

In Table 2, Option 1 has the lowest first cost among the alternatives by a large margin. If it were embodied in such a manner that it could not be separated and reused, it would need to be repurchased as an adjunct of the water heater that replaces the first unit at the end of 14 years average life. In comparison, Options 2 and 3 each have a single first cost that, other than any repair or service work they might need, is the present value (PV) of their 28-year life-cycle cost.

Assuming 3\% inflation for 14 years into the future, the cost of Option 1 would be $1.03^{14}$ or 1.51 times its present day cost. The total outlay for two GFA controller units would be $\$ 173.62$ over this time. If the homeowner nets $4 \%$ interest on investments, he would need to invest an amount equal to $1.03^{14} / 1.04^{14}$ times the future cost of Option 1, or $\$ 91.14$ to pay for it 14 years from now. Combining these costs on a PV basis, the 28-year life-cycle cost of the GFA controller in Option 1 would be $\$ 160.24$ which is still the least PV of the three options. The remarkably larger first cost of Option 3 appears to eliminate it from further consideration.

\subsubsection{Option 1 Recyclable}

A variant of Option 1 could be an after-market controller identical to Option 2 except for its housing and the engineered heat sink. Assuming that it would require professional labor to install and also be subject to an inspection fee, its first cost would be only about $\$ 9.20$ less than Option 2, or $\$ 234.55$. As such, it could be removed and reused at the end of the first water heater's life. At that time, its reuse would incur the cost of installation labor and an inspection fee. On the bases described above, the 14-year inflated value of these costs would be about $\$ 300$ bringing the life-cycle PV to approximately $\$ 330$ compared to $\$ 243.75$ for Option 2. This shows clearly that Option 1 has the least life-cycle cost only when it is built in by the OEM and is made to be expendable at the appliance's end of life.

\subsubsection{Note on Inspection Fees}

A survey of inspection fees charged by local authorities to control the quality of construction and appliance installation showed that they vary widely across the country with some indication that higher fees are common in relatively richer communities. Inspection fees for domestic water heaters were found to range from $\$ 10$ to about $\$ 90$. The fees considered in Table 2 reflect the order of magnitude charged by communities comparable in size and demographic attributes to the Tri-Cities of Washington. For example, the current fee for water heater inspection in Kennewick, WA is $\$ 19.50$. Any error (likely to be under-estimation) in the assumption of fee cost would increase the cost of all options relative to the nonrecyclable variant of Option 1. However, such errors would not change the relative ranking of the options as discussed above.

\subsection{Conclusions}

The GFA controller configuration designated as Option 1, when installed by the original appliance manufacturer, is estimated to have the lowest first and life cycle cost among the alternatives but could be slightly more prone to heat aging because of its proximity to the hot water tank. This can be mitigated by 
applying good engineering to component selection and ratings, and to the thermal design of the controller. The alternative of employing Option 1 as a recyclable controller has a life-cycle cost considerably more than Option 2 because its reuse at the end of the first water heater life involves expensive labor and a second inspection fee.

Option 2 uses the identical GFA electronic components of the first alternative but mounted in a separate nearby electrical enclosure. The first cost of this option is higher than that of Option 1 principally because it requires a more expensive housing, after-market labor for installation and an additional inspection fee. Principal advantages of this alternative include (1) the physical protection afforded by the enclosure, (2) internal operating temperatures close to normal room temperature $\left(\sim 20^{\circ} \mathrm{C}\right)$ that is conducive to long life reliability, and (3) reliable life expectancy more than adequate to span two lifetimes of an average water heater. With the ability to seal the enclosure against dirt, moisture and casual opening and/or tampering, a non-professional would also be denied the ability to interfere with the functions of the electronic components.

Option 3 places the GFA controller in the vicinity of and in communication (e.g., using radiofrequency or optical fiber) with the breaker that protects the water heater electrical circuit. An advanced breaker would be required to switch power to the water heater on and off according to commands received from the GFA controller. Variants of this include placing GFA components in void spaces inside the household electric distribution panel or in a separate enclosure nearby.

Placing GFA components inside the distribution panel would be equivalent to Option 1. Both schemes essentially seek the cost advantage of avoiding a dedicated enclosure by placing GFA equipment in containment built for another purpose. While the distribution panel offers a less stressful thermal environment than that experienced by Option 1, most are typically full of circuit breakers and wiring. It is doubtful whether GFA components could be made to fit inside in a manner that would meet code or UL certification requirements.

Placing the GFA controller in a box adjacent to the circuit breaker panel would offer Option 3 the advantages of Option 2 but at considerable extra cost for the advanced circuit breaker and a necessary communication link to the GFA controller. While this arrangement would save the cost of the relay or power electronic switch component of the GFA controller, remote controlled circuit breakers such as the Micrologic units cost greater than an order of magnitude more than conventional domestic breakers and do not fit into typical household breaker panels. Their versatility is wasted in the GFA application. No Micrologic-type of breaker has been found that is capable of switching 25 Amperes and 240 Volts, a typical requirement of this application. A simpler breaker costing less could conceivably be developed for this application but would need all the investment, development, certification and marketing typical of a new product introduction.

A conventional breaker is primarily a circuit protective device that normally resides in its "open" or "closed" state for long periods. It is not designed for switching at the frequency (possibly several times a day) the GFA controller could require. Yet this capability exists in available relays that cost, at most, a few dollars. With this capability so affordable, there is no cost or reliability justification to seek a comparable level of performance in a sophisticated breaker that will plug into a standard domestic distribution panel. 
From consideration of the above, Option 1 is determined to be the preferable choice from the aggregate perspective of having adequate reliability and life expectancy combined with the lowest life cycle cost. Option 2 is the runner up with life expectancy extending over two appliance lifetimes tending to compensate a higher life-cycle cost. Option 3 can be eliminated from further consideration because of its relative complexity, lower reliability and exorbitant cost.

\subsection{References}

Appliance Magazine. 1995. September 1995 issue cited in Market Disposition of High-Efficiency Water Heating Equipment, by Arthur D. Little, Inc. for the U.S. Department of Energy, NTIS PB97-145379, November 1996.

Digikey. 2009. "Digikey Corp.—Electronic Components Distributor-United States Home Page." Digikey Corporation. Available online at http://www.digikey.com/.

Eng-Tips Forums. 2009. "Eng-Tips Forum: Intelligent Work Forums for Engineering Professionals." Available online at http://www.eng-tips.com/userinfo.cfm?member=designchain

Hammerstrom D, J Brous, G Horst, T Oliver, C Eustis, OM Järvegren, RG Pratt, R Kajfasz, P Michie, W Marek, and RL Munson. 2007. Pacific Northwest GridWise ${ }^{\mathrm{TM}}$ Testbed Demonstration Projects; Part II. Grid Friendly ${ }^{\mathrm{TM}}$ Appliance Project. PNNL-17079, Pacific Northwest National Laboratory, Richland, WA. Available at http://gridwise.pnl.gov.

Schneider Electric. 2009. "Automation and Control Area." Schneider Electric. Available online at http://www.schneider-electric.com/sites/corporate/en/products-services/automation-control/automationcontrol.page.

Underwriters Laboratories Inc. 2007. "Standard for Safety for Temperature-Indicating and -Regulating Equipment, UL-873.” Underwriters Laboratories Inc., Northbrook, Illinois. 


\section{Distribution}

No. of

$\underline{\text { Copies }}$

1 Paul Ferron

Bonneville Power Administration

Mail Stop TPP-DITT-2

Vancouver, WA

1 Conrad Eustis

Portland General Electric

121 SW Salmon

Portland, OR 97204

1 Shannon McCormick

Puget Sound Energy

4355-110th Ave NE

Bellevue, WA 98004
No. of

Copies

8 Local Distribution

Pacific Northwest National Laboratory

DJ Hammerstrom K1-85

JG DeSteese K5-20

CH Imhoff $\quad$ K1-98

EO Jones K2-06

MCW Kintner-Meyer K1-85

$\mathrm{N} \mathrm{Lu}$ K1-85

Y Makarov K1-85

CJ Raymond K1-85 




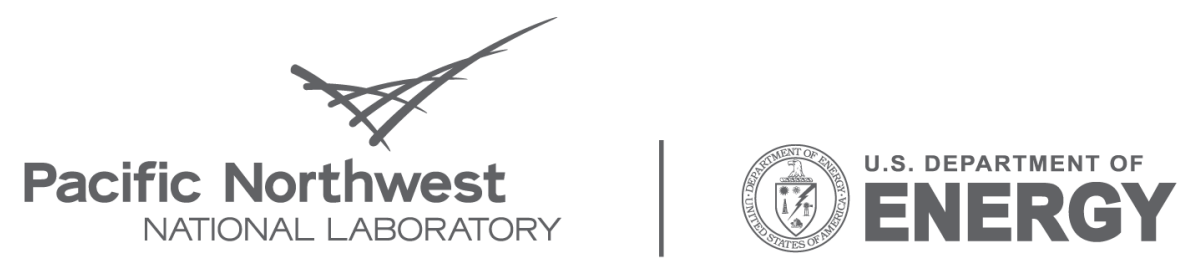

Proudly Operated by Battelle Since 1965

902 Battelle Boulevard

P.O. Box 999

Richland, WA 99352

1-888-375-PNNL (7665)

www.pnl.gov 